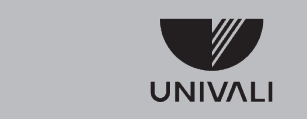

UNIVERSIDADE DO VALE DO ITAJAí

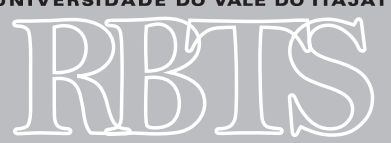

Revista Brasileira de Tecnologias Sociais
1 Doutora em Antropologia Social/ UFSC. Professora PMGPP/UNIVALI. Pesquisadora NAUI/UFSC.

$<$ ? > Doutor em Psicologia. Professor do Curso de Psicologia/UNIVALI.

$<$ ?> Acadêmica do Curso de Psicologia/ UNIVALI.

$<$ ?> Acadêmica do Curso de Psicologia/ UNIVALI.

\section{Ressignificação da identidade no processo de imigração haitiana: uma pesquisa numa cidade do sul do Brasil}

\section{Resignification of identity in the process of haitian immigration: a study conducted in a city in the South of Brazil}

\author{
Micheline Ramos de Oliveira ${ }^{1}$ \\ JOÃO SARDÁ JUNIOR ${ }^{2}$ \\ Vanessa Brenerk Marinho Benfica ${ }^{3}$ \\ Andréia Naiana dos Santos Silva Royer ${ }^{4}$
}

Resumo: Vive-se um período em que as imigrações estão mais frequentes, e pessoas das mais diversas origens se encontram em espaços de culturas diversas. Recentes ondas imigratórias vêm ocorrendo no Brasil pelos haitianos em função da ajuda humanitária oferecida ao Haiti após o terremoto ocorrido no início de 2010. Esta pesquisa buscou compreender como ocorre o processo de ressignificação da identidade dos imigrantes haitianos na cidade de Balneário Camboriú, no Estado de Santa Catarina. Esta pesquisa, de natureza qualitativa, foi efetuada por meio de entrevista exploratória submetida à análise de conteúdo. Sete imigrantes haitianos residentes na cidade de Balneário Camboriú participaram da pesquisa. A ressignificação da identidade dos imigrantes haitianos aparece na busca pela qualidade de vida aqui no Brasil; pela adaptação à cultura e alguns objetivos futuros, como trazer seus familiares para o Brasil, ter documentos legais, adquirir bens de consumo e um emprego que garanta um salário melhor. O que se nota é que, assim como os brasileiros possuem perspectivas para uma vida melhor, o mesmo ocorre com os haitianos que imigraram de uma situação caótica em seu país para outro, em que acreditam ter mais chances. Os resultados indicaram que há uma discrepância quanto à profissão exercida no Haiti e à atual profissão.

Palavra Chave: Imigração haitiana. Identidade. Ressignificação.

Abstract: We live in a period in which the immigration is becoming more frequent, with people from many different backgrounds coming together in spaces of different cultures. Recent waves of Haitian immigration have been occurring in Brazil, due to the humanitarian aid provided to Haiti after the earthquake in early 2010. This research sought to understand the process of reframing the identity of Haitian immigrants to the city of Balneário Camboriu, in the State Santa Catarina. A qualitative study was conducted, through exploratory interviews with seven Haitian immigrants living in the city of Balneário Camboriú. The interviews were then submitted to content analysis. Reframing the identity of Haitian immigrants appears in the search for quality of life here in Brazil; through adaptation to the culture and some future goals to bring their 
family members to Brazil, gain legal documents, acquire consumer goods, and get a job that guarantees a better salary. What we see is that just as the Brazilians have prospects of a better life; the same is true for Haitians who have immigrated from a chaotic situation in their own country to a country where they believe they have a better chance of success. The results indicated a discrepancy in terms of the type of jobs done in Haiti and the immigrants current jobs.

Keyword: Haitian immigration. Identity. Reframing.

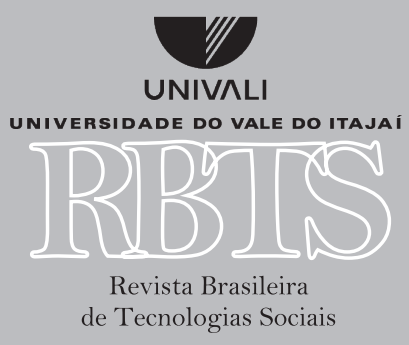




\section{INTRODUÇÃO}

Os deslocamentos humanos nunca foram tão frequentes e nunca pessoas das mais diversas origens se encontram em espaços de culturas tão distintos daquele das suas culturas de origem (DANTAS et al., 2010). O termo imigração pode ser definido como o deslocamento de pessoas de seu local de origem na busca de trabalho ou de uma melhor qualidade de vida, sendo que a maior parte destas migrações ocorre por meio de pessoas e de regiões menos favorecidas (FRANKEN et al., 2009).

Segundo Soares (2004), Amorim (2012), Rodrigues (2013), Fernandes e Castro (2014), a imigração internacional tem por base fatores econômicos, políticos, sociais e humanitários. Ainda segundo estes autores, o fluxo de migração se caracteriza pela busca de melhores condições de vida superando a emigração de quem busca ocupar um espaço em centros comerciais, servindo-se como mão de obra.

Para Dantas et al. (2010), o contato contínuo com outra cultura, que ocorre no processo de imigração, pressupõe um conflito/crise e uma posterior adaptação ao novo ambiente cultural. Mesmo com conotação de conflito/crise, os imigrantes ainda optam por esse caminho na busca de uma vida melhor, no entanto cabe compreender os fatores que impulsionam a imigração internacional nos dias de hoje.

A população haitiana, no dia 12 de Janeiro do ano de 2010, foi surpreendida por um terremoto que teve um grande impacto num país já assolado por diversos problemas sociais e econômicos e, consequentemente, ocasionando problemas psicológicos (GUIMARO et al., 2013). Na busca por melhores condições de vida, uma parte da população imigrou para outros países (AMORIM, 2012).

Para a Psicologia, como uma das áreas científicas interessadas neste fenômeno, tornase importante investigar aspectos que dizem respeito à constituição psíquica do ser humano, procurando compreender o processo da construção da identidade e como ela se ressignifica nos mais diversos contextos.

Nas bases de dados Bireme, sem especificar um período de tempo, utilizando os termos imigração e identidade, foram encontrados 186 artigos científicos. Utilizando as palavras-chave imigração e Haiti, foram encontrados 111 artigos. Utilizando os termos imigração, identidade e Brasil, foram encontradas na mesma base de dados apenas 15 artigos, e quando foi utilizado os termos imigração haitiana, apareceram apenas 06 artigos. Quando os termos imigração e Santa Catarina foram utilizados, foram encontrados apenas 06 artigos. O reduzido número de artigos reflete a escassez de material científico sobre este objeto de pesquisa e a importância de produzir conhecimento sobre o assunto, em especial sobre a imigração haitiana em Santa Catarina e como se dá este processo para o imigrante haitiano.

A compreensão teórica do objeto de estudo dessa pesquisa estará alicerçada nos conceitos de identidade e ressignificação.

A identidade é um processo psicológico pelo qual um indivíduo assimila um aspecto, uma propriedade, um atributo do outro e se transforma, total ou parcialmente, segundo o modelo dessa pessoa. [...] nosso senso de identidade é desenvolvido a partir da conexão com os outros. (DANTAS et al., 2010).

Para Dias (2011), a identidade está ligada ao reconhecimento do “eu”. Para Taylor (1994, p. 41-42), a identidade seria a percepção que a pessoa possui de si mesma, reconhecendo características 
que a definem como ser humano. Neste sentido, o reconhecimento ou não reconhecimento por parte do outro é central no processo de construção da identidade. Para Taylor (1994, p. 41-42), “o não reconhecimento ou o reconhecimento inadequado pode prejudicar e constituir uma forma de opressão, aprisionando certas pessoas em um modo de ser falso, deformado ou reduzido”.

Partindo do pressuposto de que a identidade se constitui na relação com o outro, Oliveira (1976) faz uma análise do processo de identidade do imigrante de uma forma mais específica. Segundo o autor, o imigrante se afirma ao "negar" a identidade do outro, dando um sentido de etnocentricidade, ou seja, é quando uma pessoa ou um grupo se afirma como tal e o faz como meio de diferenciação em relação a alguma pessoa ou grupo com que se defronta.

Para Aguiar e Orzella (2006), os indivíduos constituem-se a partir da sociedade e a sociedade a partir do sujeito. Nesse processo de construção social vão se formando significados e a atividade psíquica passa pelo processo de reestruturação a partir da internalização dos fatos. Partindo destes pressupostos, o processo de reestruturação da identidade pode ser compreendido por meio do conceito de ressignificação.

O processo de ressignificação da identidade pode ser definido como a busca em sentir-se pertencente, sentir-se adequado ao local onde se encontra, ou ainda construir um novo significado/ sentido à vida. Para o imigrante esta necessidade torna-se mais evidente, pois este em geral está em local culturalmente distinto do seu de origem. "Convém ressaltar que a identidade pode ser construída através de um processo de significado com base nas características culturais interrelacionadas". (SCOLARI, 2006).

Com relação à identidade de imigrantes e aos aspectos que englobam esse processo de significado, Kreutz (1999) afirma que este ocorre na constituição de sujeitos e de grupos, sendo um elemento constituinte de práticas sociais e, ao mesmo tempo, as práticas sociais vão reconstituindo a configuração étnica. Ao se deslocar para outras possibilidades, se é remetido a rever valores, considerando e significando-os, por vezes abolindo ideias e conceitos, e passando a se comunicar de maneira que possa ser visto e compreendido (AMORIM, 2012).

Nesse processo de imigração ocorre invariavelmente um processo de adaptação. Não somente no Brasil, mas em outros países o imigrante em busca de novas oportunidades se submete aos ditos "subempregos", trabalhos de menor valor. Para Scolari (2006), o trabalho passa por várias formas opressivas, deixando de ter um caráter humanizador para tornar-se uma forma de sobrevivência.

A importância de discutir o tema imigração sob a perspectiva da construção da identidade do imigrante reside no fato de recentemente o Brasil ter oferecido ajuda humanitária ao Haiti após o terremoto ocorrido no país no final do ano 2010. A partir disto tem ocorrido uma crescente imigração de haitianos no país, inclusive na região do Vale do Itajaí.

A partir dos conceitos expostos, o presente estudo investigou como ocorreu o processo de imigração em um grupo de haitianos residentes em Balneário Camboriú, Santa Catarina, bem como os recursos utilizados no processo de inserção social e quais foram os aspectos que contribuíram para a ressignificação da identidade a esta nova cultura.

\section{METODOLOGIA}

Essa pesquisa exploratória-descritiva de natureza qualitativa, utilizando como método a análise de conteúdo, visa investigar o fenômeno estudado de maneira aberta e flexível, levando 
o entrevistador a conhecimentos que supostamente não teria pensado por si mesmo (QUIVY; CAMPENHOUDT, 2005).

Participaram da pesquisa sete imigrantes haitianos residentes em Balneário Camboriú - SC. Foi estabelecido este número de sujeitos, uma vez que o conceito de saturação na pesquisa qualitativa preconiza que, após um número de entrevista, o conteúdo emergente tende a se repetir (FONTANELLA et al., 2011).

A coleta de dados foi realizada por meio de entrevista semiestruturada. Os dados obtidos foram analisados, utilizando-se da técnica de análise de conteúdo. A partir das categorias iniciais emergiram também subcategorias.

\section{RESULTADOS E DISCUSSÃO}

Participaram da pesquisa sete sujeitos do sexo masculino, com idade entre 27 e 46, que anteriormente atuavam como profissionais liberais (ex: comerciantes ou técnicos) e atualmente atuam em cargos como repositor de supermercado, frentista de posto de gasolina ou coletor de lixo). As entrevistas em geral foram realizadas em 30 minutos, sendo gravadas e posteriormente transcritas.

Os resultados foram agrupados em cinco grandes categorias, e algumas subcategorias, a saber, Processo de Imigração (Desastre Natural e Situação Econômica do Haiti, Acessibilidade no Processo de Imigração, Empregabilidade, Identificação com o país); Identidade (Identidade Profissional Anterior, Identidade Profissional Atual, Recursos Financeiros); Integração dos Valores Culturais (Adaptação ao Novo Ritmo de Vida no Brasil, Opções de Lazer); Crenças/ Significados (Educação e/ou Perspectiva, Religiosidade, Ressignificação) e Distância da Família e Recursos/Rede de Integração, (Legalização da Imigração, Apoio e Receptividade do Brasileiro).

A primeira categoria definida como processo de imigração engloba as subcategorias desastre natural e situação econômica do Haiti, acessibilidade no processo de imigração, empregabilidade, identificação com o país, e se refere à percepção dos imigrantes sobre o desastre ocorrido no Haiti no ano de 2010, passando pelo acordo político realizado entre Brasil e Haiti e o processo de imigração dos entrevistados, em que se percebe também a identificação dos haitianos com o Brasil.

O Haiti é um país que já enfrentava muitas dificuldades econômicas antes do terremoto no ano de 2010, como aparece nas falas dos entrevistados:

S3: "Eu saí por causa da situação, porque o Haiti antes já não tava muito bom, e porque a hora se passou o terremoto." (SIC)

S6: "Ocorreu uma catástrofe." (SIC)

S4: Terremoto lá no Haiti bastante pessoa morrer lá então a crise ficou maior.” (SIC)

A situação do Haiti em crise econômica e social e o abalo sísmico foram fatores que contribuíram para o desencadeamento da imigração haitiana em grande número a outros países. No ano de 2011 a população haitiana apresentava uma quantidade menor de imigrantes no Brasil em relação a outros países (AMORIM, 2012; RODRIGUES, 2013). Atualmente há um fluxo maior de imigração decorrente da ajuda humanitária oferecida pelo Brasil (FERNANDES; CASTRO, 2014; MORAES et al., 2013; RODRIGUES; 2013). 
O tema acordo político também emergiu na fala dos entrevistados, podendo ser representada pela fala do entrevistado:

S4: "E o presidente atual presidente René Garcia Préval negociou com Brasil para abrir fronteira para que os haitianos viesse para cá.” (SIC)

S2: "Governo aqui com governo Haiti consulta para ajuda todo haitiano a cá em Brasil para ir trabalha para ajudar família no Haiti." (SIC)

A ajuda humanitária oferecida pelo governo brasileiro, estabelecida pela Resolução Normativa $n^{\circ}$ 97/2012, contribuiu de forma importante para a imigração haitiana, bem como a oferta de trabalho em Santa Catarina também foi determinante nesse processo, assim como a afinidade com os valores e a cultura brasileira, embora neste momento o Brasil não se encontrasse preparado para tal desafio humanitário (RODRIGUES, 2013; PACÍfICO; PINHEIRO, 2013). Conforme Fernandes e Castro (2014), o Brasil foi um dos países escolhidos para a imigração haitiana devido às oportunidades de trabalho que se apresentavam na época após o terremoto; às construções em execução devido à Copa do mundo e à baixa taxa de desemprego apresentada.

Para a maioria, seis dentre os sete participantes, a empregabilidade foi um fator determinante na mobilização dos haitianos para a vinda ao Brasil. Isto pode ser percebido na fala de:

S4: "Lá companhia veio e pega como 84 haitianos lá." (SIC)

E no discurso de:

S6: "Eu tava lá no Acre e lá chegava alguma pessoa da companhia que tava procurando pessoas para trabalhar.” (SIC)

Pode-se perceber aqui que a existência de oferta de emprego de certa forma contribuiu para a imigração desta população para Santa Catarina.

A imigração internacional tem por base fatores econômicos, políticos, sociais e humanitários (SOARES, 2004; AMORIM, 2012; RODRIGUES, 2013; FERNANDES; CASTRO, 2014). No caso dos imigrantes haitianos este processo teve início com a crise financeira do Haiti, sendo que este processo se agravou com o terremoto de 2010, no entanto, para Moraes et al. (2013) e Rodrigues (2013), falar sobre o processo imigratório significa que os fatores determinantes, como o terremoto ou a baixa economia haitiana, são interdependentes, não devendo ser avaliados por uma única causa. A cidade de Brasiléia serve como uma das portas de entrada ao país, onde muitos imigrantes aguardam a regularização de sua permanência provisória no Brasil, muitas empresas vão até esta cidade em busca de mão de obra (MORAES et al., 2013; FERNANDES; CASTRO, 2014).

Embora outros países oferecessem abrigo aos haitianos, a decisão pelo Brasil aparece na fala do entrevistado:

\section{S5: "Porque nós sempre é fanático por Brasil." (SIC)}

Nesta fala, despontam aspectos que referem afinidade com o país antes mesmo que houvesse a necessidade da imigração em massa. Quando perguntado aos entrevistados a possibilidade de imigrarem para outros países, fica claro que não há vontade de saírem do Brasil, isso se evidencia na fala de:

S2: "Eu quero a Brasil porque me gusta Brasil... Eu quero a ficar." (SIC) 
Muitos haitianos passaram por outros países que também ofereceram facilidade de permanência, no entanto, para muitos imigrantes, o Brasil foi o destino final. Para Fernandes e Castro (2014), subtende-se que a facilidade de permanência não é o único motivo da imigração haitiana nas diversas regiões brasileiras. Dentre diversas razões, o Brasil tem sido escolhido pelos haitianos por ser um país que possui muitas Organizações Não Governamentais (ONGs) inseridas no Haiti, inúmeros projetos de desenvolvimento humano e estrutural e por também ser o líder na Missão das Nações Unidas para a Estabilização no Haiti - MINUSTAH (MORAES et al., 2013). Conforme Diniz (2005) e Verenhitach et al. (2007), a MINUSTAH foi criada pela Resolução ${ }^{\circ}$ 1.542, de 30 de abril de 2004. O Brasil como líder desta missão objetiva desenvolver "ações que visam o restabelecimento da paz e segurança, à erradicação da fome e miséria, ações voltadas à saúde e ao meio ambiente” no Haiti, apontam Verenhitach et al. (2007).

A crescente onda imigratória haitiana para o Brasil tem despertado na população brasileira uma discussão. De um lado há aqueles que se preocupam com a segurança institucional, com o acúmulo capital e políticas de imigração; enquanto do outro lado há uma inquietação em relação a uma nova política de imigração voltada aos direitos e ao reconhecimento social dos imigrantes haitianos (AMORIM, 2012; CORREIA et al., 2013). No entanto, apesar desta ambiguidade, de maneira geral, o povo brasileiro é receptivo e acolhedor (FERNANDES; CASTRO, 2014).

A segunda categoria, definida como identidade, engloba as subcategorias identidade no trabalho anterior e identidade no trabalho atual e recursos financeiros. A diferença existente entre a profissão atual e a anterior sugere a existência de uma discrepância profissional, uma vez que hoje estes estão ocupando vagas consideradas no mercado de trabalho brasileiro como funções de pessoas que não possuem qualificação adequada para outras áreas profissionais, entretanto estes as tinham. Isto pode ser percebido na fala de:

S5: "Minha vida no Haiti era mais ou menos... Hum, não era... Como te digo... Eu morava muito, muito bem... A gente trabalhava direito muito bem, eu era marceneiro, carpinteiro...” (SIC)

Alguns eram professores no Haiti:

S1: "Minha profissão... ensinava informática tipo Word, Excel, Power Point e eu trabalha com isso lá.” (SIC)

Os participantes se encontravam em um momento em que estavam trabalhando ativamente em seu país de origem, contribuindo com sua sociedade e produzindo conforme suas necessidades. Ao saírem de seu país, esta população se inseriu em uma nova realidade. Além das mudanças culturais, estes haitianos experimentam a mudança de posição social referente ao serviço que eles hoje prestam aqui no Brasil (MORAES et al., 2013). A identidade social compreende aquilo que o sujeito representa para seu grupo e ao mesmo tempo é reconhecida pelo outro, unificando e integrando a pessoa ao reconhecimento e ao pertencimento da sociedade (WATARAI; ROMANELLI, 2005; LIMA et al., 2004).

Além de estarem em subempregos, seis entre os sete entrevistados trabalham em dois lugares em turnos alternados, como relata:

S4. "Só trabalho... Já eu trabalho aqui em supermercado Imperatriz e eu trabalho também na Coneville em outro horário. Aqui trabalho na reposição da loja." (SIC)

Eles possuem certo receio quanto à perda de um trabalho, conforme relata: 
S1: "Haitiano tem que trabalhar certinho não perder um dia - se você perde um dia de trabalho é bem pior... tem que cuidar se não eles mandam embora... Tem que trabalhar certinho tem que respeitar horário de serviço." (SIC)

Para Lima et al. (2004), a identidade de trabalhador passa por uma relação dialética entre o homem e a sociedade. Para os haitianos, além dos recursos financeiros que o trabalho possibilita, ter dois empregos significa buscar uma melhor qualidade de vida, que foi um dos motivos que os impulsionaram a imigrar (FRANKEN et al. 2009; FERNANDES; CASTRO, 2014). O trabalho também é uma forma de ajuda e de movimento na economia haitiana, pois estes imigrantes enviam dinheiro aos parentes no Haiti (RODRIGUES, 2013).

Para os entrevistados, a perda do emprego pode resultar na criação de um estereótipo associado à falta de comprometimento com o serviço, ocasionando perda de credibilidade do haitiano e, consequentemente, do grupo que ele representa. Para Bock (1999) e Lima et al. (2004), a pessoa é construída e ajuda a construir a realidade social na qual se encontra, facilitando ou impedindo o desenvolvimento dela e do contexto no qual se insere, atuando, ampliando e modificando a realidade. Para o homem social, o trabalho traz em si significados como realização, disciplina, sobrevivência e transformação (LIMA et al., 2004).

Os chamados subempregos aqui no Brasil, além do estigma enraizado, também são marcados por baixos salários e exploração da mão de obra. Isto pode ser percebido na fala de:

S3: "Aí que precisar de dinheiro tem que trabalhar e ganhar mais dinheiro, porque aqui pagando muito pouco.” (SIC)

E de:

S2: "Por que a cá em Brasil se o pessoa pensa que um servício pagar muito... aí no trabalha." (SIC).

Estas falas retratam uma realidade vivida por todos os sete entrevistados, inclusive um dos entrevistados menciona que a má remuneração é uma realidade brasileira.

Conforme mencionado anteriormente, o Haiti, muito antes do terremoto do ano de 2010 , possuía sua política e sua economia instáveis. Para os haitianos, vir para o Brasil é a tentativa de um recomeço (MORAES et al., 2013; RODRIGUES, 2013). A realidade brasileira é revelada na experiência dos imigrantes que recebem um valor salarial abaixo e imerecido diante de uma jornada longa de trabalho. O mercado de trabalho brasileiro explora a mão de obra haitiana, ainda mais quando este está ilegal, desta forma eles possuem pouco ou nenhum direito trabalhista (MORAES et al., 2013).

A adaptação ao novo ritmo de vida no Brasil aparece de forma angustiante na fala do entrevistado que, em meio a lágrimas, relata:

S6: "Minha vida, no está boa porque o servicio pagam poco e o aluguel és caro, mucho caro, trabalho aqui e só recibo mil e cem e pago 900 de aluguel." (SIC)

E também na fala de:

S3: "[...] aí que pagar aluguel, porque trabalhando aqui é salário 1.015,00, e pagar aluguel e comprar leite pra criança, e salário no vai dá.” (SIC)

Para os haitianos, está sendo muito difícil receber um salário que apenas pague seu aluguel.

Cabe aqui lembrar que o Brasil luta por melhorias econômicas em prol da população brasileira, que também sofre com os baixos salários e vive em busca pela residência particular 
na tentativa de se livrar do pagamento de aluguel e, segundo Rodrigues (2013), a mão de obra do imigrante contribui para o crescimento do Brasil. Vale salientar que pensar em assegurar os direitos dos imigrantes é também pensar em nosso desenvolvimento, para tanto, o país tem um projeto de lei para estrangeiros em trâmite no Congresso Nacional, onde consta que a imigração deve ser tratada como um direito humano, dando a entender que o país tem o interesse em criar estruturas e políticas igualitárias para o imigrante.

A categoria integração dos valores culturais engloba as subcategorias adaptação ao novo ritmo de vida no Brasil e opções de lazer. Quanto a momentos de lazer, estes parecem não fazer parte da vida dos entrevistados que, ao serem interrogados sobre quais atividades utilizavam para se divertirem ou descansarem, respondiam que não havia esses momentos, como se pode ver na fala de:

S3: "No, eu no faz nada só fica em casa, olhar televisão... Assisto televisão, se eu tem algum amigo vou na casa dele para conversar um pouco com ele. Se tem tempo que no escucha mia mãe liga a mia mãe por telefone e fico em casa, no faz mais nada.” (SIC)

Para quem possui dois empregos, dificilmente há possibilidade de ter uma folga durante o dia, como é o caso de:

S1: "Eu to de folga em um serviço hoje minha mulher ela ta mal eu tenho tempo de ir no hospital com ela. Eu dorme quatro horas só... Depois tenho aquele outro compromisso.” (SIC)

Além de ter pouco tempo de descanso, o entrevistado ainda precisa levar a esposa ao hospital, no entanto em sua fala soa um ar de alívio por ter este momento disponível para acompanhá-la até o pronto-socorro.

Pensar sobre momentos de lazer e descanso se entrelaça à temática de qualidade de vida. No entanto falar sobre qualidade de vida requer primeiramente saber quais as percepções e os conceitos estão envoltos nesta questão. Para Franken et al. (2009), qualidade de vida passa por um plano individual de construção histórica, cultural e classe social. Cada sociedade possui um parâmetro do que é qualidade de vida, diferentemente de outra sociedade. A tradição, o valor e as necessidades ditam quais aspectos são considerados válidos como bom ou ruim e, por último, a situação social, ou as condições econômicas vinculam satisfação material ao bem-estar (FRANKEN et al., 2009).

Quanto à categoria crenças e significados, a integração dos valores culturais, os conteúdos emergentes foram subcategorizados em educação e/ou perspectiva, religiosidade, ressignificação e distância da família.

Nas falas dos participantes, identifica-se a educação formal como um meio de viabilizar uma melhor perspectiva de vida. Percebe-se este aspecto na fala de $\mathrm{S} 1$ ao afirmar que precisa:

S1: "[...] deixar um serviço pra ir pra escola pra estudar... pra poder mudar minha vida ... pra ficar uma vida melhor... um quarto com refrigerador... um carro novinho... mais qualidade pra poder ganhar melhor." (SIC)

Também no que se refere à perspectiva, além de pretenderem continuar morando no Brasil, os entrevistados buscam qualidade de vida aqui, como afirma:

S6: "Reduzir hora de trabalho... Trabalha muito." (SIC)

E por não terem a revalidação de suas profissões no Brasil, compreendem que a educação formal contribuirá para as conquistas materiais, bem como de estabilidade profissional. 
A literatura aponta que a educação formal não é uma meta distante de ser alcançada pelos imigrantes, pois com a concessão do visto humanitário, os haitianos detêm basicamente os mesmos direitos dos brasileiros, como direito à saúde, à educação e à autorização para trabalhar. Na esfera das políticas públicas para educação, Institutos Federais de Educação, Ciência e Tecnologia da Região Norte oferecem formação aos haitianos, com o fim de promover sua integração com brasileiros e inseri-los no mercado de trabalho local, segundo a assessoria de comunicação social do Ministério da Educação no ano de 2012 (PACÍFICO; PINHEIRO, 2013).

A religiosidade e o sustento de uma fé são notáveis na fala dos participantes. Alguns atribuem as conquistas de sua vida ao fato de terem uma prática religiosa, como afirmam:

S1: "Graças á Deus eu sempre está trabalhando/Eu soy Cristiano eu sou Batista." (SIC)

S2: "Sempre, sempre tá trabalhando graças á Deus [...] Graças á Deus a tá eu buscando mi família eu tá trabalhando.” (SIC).

A imigração surge como um fator estressante na realidade dos haitianos, e o apego religioso neste momento emerge como lida desse fator, como aponta Tarunus (2011):

Os fenômenos religiosos e espirituais recebem atenção como sendo um recurso amortecedor perante as tensões e os estresses. A fundamentação subjacente é que pela razão lógica e teórica, as atribuições a um propósito de Deus podem ajudar os indivíduos a dar sentido a eventos estressantes e podem facilitar a sua adaptação a circunstâncias estressantes. Assim, os que atribuem as circunstâncias estressantes a um propósito de Deus (Força Suprema, Espírito Santo, etc.) sentem-se menos desconfortáveis.

Mediante a alta vulnerabilidade financeira, de saúde e de adaptabilidade a uma nova cultura, compreende-se a religiosidade como via de escape aos problemas vivenciados e uma forma de sustentar a esperança de dias melhores.

Na subcategoria ressignificação, percebe-se o interesse dos entrevistados em se apropriar ao idioma brasileiro, conforme dito por:

S4: "Eu sempre mexer em Google, pra ver se consegue pra aprender um pouco mais da língua do português.” (SIC)

Sobre a constituição dialética do homem, pode-se afirmar que o plano individual não constitui mera transposição do social. O indivíduo modifica o social, transforma o social em psicológico e, assim, cria a possibilidade do novo. Isso posto, pode-se afirmar que a linguagem seria o instrumento fundamental nesse processo de constituição do homem (AGUIAR; OZELLA, 2006).

A análise das falas retrata um processo de ressignificação que pode ser percebida na fala do entrevistado S6, a confiança em si para ir em busca de suas próprias conquistas ao afirmar:

S6: "Eu sinto feliz, de tener saúde e poder trabalhar." (SIC)

A fala de $S 6$ retrata seus recursos internos de adaptação à nova realidade, bem como o significado que é dado a ela.

Para Aguiar e Ozella (2006), os signos e os instrumentos psicológicos são constitutivos do pensamento não só para a comunicação, mas também como meio de atividade interna. A palavra, signo por excelência, representa o objeto na consciência. Com isso os autores ainda afirmam que os signos representam uma forma privilegiada de apreensão do ser, do pensar e do agir do sujeito. 
Na fala dos entrevistados, identificou-se o comprometimento com a sua família que ainda vive no Haiti. Quanto à distância de sua família, os participantes demonstram saudade, como observado nas falas de:

S3: "Todos mi parente, mi irmã, mi irmã, mia mãe tão tudo lá [ ... Mia mãe e mia família tá ficando muito longe de mim." (SIC)

S4: "Minha mãe sofre, meu pai sofre, meus irmãos, minhas irmãs... Tão lá tudo... Minhas duas filhas.” (SIC).

Como esperança de viver dias melhores, os haitianos contam com a segurança legal da Resolução Normativa $n^{\circ}$ 97/2012, que dispõe sobre a concessão do visto permanente, não apenas para quem solicitar o visto, mas também aos cônjuges e aos parentes, pois a unidade familiar é princípio-dever aplicado pelo Brasil aos imigrantes (PACÍFICO; PINHEIRO, 2013).

Ainda no que se refere ao fato de estarem longe de suas famílias, os haitianos ressaltam o compromisso financeiro com seus parentes que estão longe, como identificado na fala de:

S3: "Pra mandar pra escola, pra comprar roupa, pra comprar tudo para ele, e se ele precisar algo amanhã e falar Pai tá precisando isso! Pagar curso para ele e pagar a universidade pra ele.” (SIC)

Quanto à categoria recursos/rede de integração, os conteúdos emergentes foram subcategorizados em legalização da imigração, apoio e receptividade do brasileiro.

A legalização da imigração é um processo burocrático e que muito preocupa os haitianos, pois eles também não podem sair do país sem antes legalizarem seus documentos aqui, a fim de garantirem seu retorno ao Brasil sem entraves na fiscalização:

S3: "Se agora eu tirê residência para depois visitar mi família... Visitar mi família." (SIC).

Os entrevistados falam da necessidade de se regularizarem como cidadãos, $S 1$ afirma:

S1: "É tem que ter identidade e CPF." (SIC).

A literatura aponta o posicionamento do Brasil com relação à imigração haitiana, bem como alguns esclarecimentos com relação à burocracia enfrentada pelos imigrantes.

Pacífico e Pinheiro (2013) relatam que o governo brasileiro, contudo, visa administrar o fluxo de haitianos no Brasil lidando com o problema humanitariamente, decidindo conceder vistos permanentes de residência por razões humanitárias. $\mathrm{O}$ visto “ $[\ldots]$ tem caráter especial e será concedido pelo Ministério das Relações Exteriores, por intermédio da Embaixada do Brasil em Porto Príncipe” (PACÍfICO; PINHEIRO, 2013). Desta forma, ressalta-se a preocupação do Governo Brasileiro em legalizar a estada desses imigrantes em solo brasileiro.

Mesmo com medidas sendo tomadas em nível de embaixadas internacionais ou de tratados governamentais, os haitianos relatam a carência no apoio assistencial em sua chegada ao Brasil, não tendo o amparo de órgãos governamentais ao chegarem em solos brasileiros, como pode ser notado na fala de:

S1: "Quando eu cheguei eu fiz tudo sozinho, ninguém me ajudou ninguém." (SIC)

E quando questionado sobre existência de algum órgão governamental ou ONG engajado na receptividade de imigrantes, $\mathrm{S} 4$ responde:

S4: "No sei se tem... Não posso falar também se no tem. Eu não conheço." (SIC) 
Como a situação dos haitianos no Brasil é bastante recente, políticas públicas e medidas para melhoria de vida dos que chegaram após o terremoto de 2010 ainda estão sendo elaboradas. O Governo Federal juntamente com os governos estaduais estão se comprometendo a ajudá-los no tocante à assistência básica (PACÍFICO; PINHEIRO, 2013).

Mesmo em meio aos relatos de descaso de políticas públicas para imigrantes, os haitianos elogiaram a receptividade do povo brasileiro. $\mathrm{S} 1$ afirmou que:

S1: "Brasileiros e brasileiras são gente boa fica tranquilo não brigando com nós... Nós caminhamos pelas ruas sem problemas... Outro país não faz isso pra nós, receber nós bem.” (SIC).

Corroborando a isso, pesquisas apontam que o acolhimento dos primeiros imigrantes haitianos em território brasileiro, que foi realizado de forma amigável, diferentemente do que ocorreu em outros destinos onde a migração haitiana foi duramente repreendida, criou a imagem de um país acolhedor, servindo de motivação para a escolha do Brasil como possível novo lar (MORAES et al., 2013).

\section{CONCLUSÃO}

Por meio das entrevistas e da literatura pesquisada, foi possível compreender o processo de ressignificação da identidade dos imigrantes haitianos no sul do Brasil.

As categorias das entrevistas aqui apresentadas viabilizaram a compreensão do fenômeno de ressignificação da identidade haitiana a esta nova cultura. Percebeu-se que o processo de imigração teve forte relação com o desastre natural ocorrido em 2010, aliado ao fator econômico do país, que já se encontrava em crise antes mesmo do terremoto. A imigração foi facilitada pela ajuda humanitária oferecida pelo Brasil, proporcionando o acesso à empregabilidade.

A identidade dos imigrantes perpassa pelas questões profissionais e constatou-se que todos os entrevistados possuem qualificações específicas, como professor de idiomas e informática, comerciantes e ourives; no entanto se percebeu certo conformismo dos cargos que eles ocupam atualmente, mesmo que não o de suas especificidades, embora alguns mencionassem o desejo de conquistar um emprego melhor, ou até mesmo a intenção de readotar a profissão já exercida anteriormente no Haiti. O desejo por essas melhorias pode ter relação com a fadiga oriunda da intensa rotina de trabalho aliada à falta de lazer e momentos de descanso.

Para os imigrantes, a permanência legalizada em nosso território tem grande importância, pois as possibilidades de melhorias de emprego estão relacionadas principalmente ao registro formal. No caso dos entrevistados, observou-se a necessidade da aquisição de documentos, como carteira de motorista e carteira de trabalho, que possibilitam o remanejamento do cargo exercido e, consequentemente, melhorias salariais e de posição social. A perspectiva de acesso à educação formal muito se relaciona com a esperança de conquistar empregos melhores.

Destacou-se o interesse dos imigrantes em se adaptar ao país, não medindo esforços para aprender o idioma, porém, pelo significativo número de haitianos na cidade de Balneário Camboriú, a convivência social destes imigrantes é restrita aos grupos de pessoas da mesma origem. Com isso muitos ainda não desenvolveram muito bem a comunicação com o Português, ocorrendo uma frequente mistura com o espanhol. No caso das mulheres, percebeu-se uma menor integração na sociedade, uma vez que muitas se ocupam de seu papel maternal, restringindo-se 
ao ambiente doméstico e, quando procuradas em suas residências, as haitianas não receberam as pesquisadoras, pois alegaram não compreender nada do que estava sendo dito por elas. E mesmo que inseridas no mercado de trabalho, as mulheres haitianas ocupam cargos que não reivindicam um contato direto com o público, limitando, desta forma, a sua comunicação com intérpretes ou outros haitianos que, por ventura, estivessem na mesma empresa. No entanto, observou-se que na região de pesquisa há indícios que a população haitiana já esteja inserida em grupos, como igrejas, empresas e associações, fortalecendo as práticas sociais (KREUTZ, 1999).

É esse aparato de análises que enriqueceu a compreensão da ressignificação da identidade dos haitianos no sul do Brasil. Os achados, embora inéditos, vão ao encontro das definições teóricas descritas na literatura, que preconizam que o processo de construção da identidade ou ressignificação é, em geral, permeado pelo trabalho, crenças, por valores culturais e inserção social (BOCK, 1999; LIMA et al., 2004).

O apoio que poderiam receber de órgãos governamentais é uma questão que muito colabora para a decisão dos haitianos em permanecerem no Brasil, mas mesmo não recebendo esse apoio, reconhecem como rede de integração a receptividade dos brasileiros e compreende-se que este aspecto seja um importante componente para que, aos poucos, os haitianos sintam-se mais inseridos e aceitos em nossa sociedade.

Em meio aos elogios referentes ao povo brasileiro, um dos participantes mencionou a intensidade do racismo na sociedade brasileira. Este não era o objetivo da pesquisa, no entanto se compreende como um importante aspecto a ser relatado. O participante da pesquisa acrescentou que em seu país os homens são chamados de Monsieur e mulheres de Madame (expressões que se referem a senhor e senhora em francês) e que veio a conhecer o termo pejorativo "negão" somente na convivência com brasileiros. Mesmo sendo vista a receptividade dos brasileiros como algo favorável aos imigrantes, deparou-se com esse contexto racial, fazendo crer na necessidade do brasileiro direcionar seu olhar imune de preconceitos ao imigrante, para que o processo de inserção, adaptação e ressignificação da identidade seja mais ameno no que se refere ao impacto emocional dos imigrantes.

De qualquer maneira, pode-se afirmar que, de modo geral, há uma satisfação dos imigrantes com o país que os recebeu, pois estes se percebem acolhidos calorosamente pelo Brasil. $\mathrm{Na}$ fala dos imigrantes que vieram para o Brasil expressa-se, inclusive, a satisfação pelo território, destacando a segurança e a qualidade da saúde como sendo excelentes no Brasil se comparadas à realidade do Haiti.

Sugere-se a continuidade da pesquisa, pois esta abriu possibilidades de outras investigações não abordadas aqui, como a participação da mulher no cenário de imigração haitiana; as relações inter-raciais; o contexto das empresas que os imigrantes atuam, bem como a satisfação com a mão de obra haitiana; a visão que o brasileiro tem do imigrante e outras inúmeras possibilidades de pesquisas que enriquecem o campo científico e aproximam o olhar do brasileiro à realidade do imigrante haitiano.

\section{REFERÊNCIAS}

AGUIAR, Wanda Maria Junqueira e OZELLA, Sergio. Núcleos de Significação como Instrumento para a Apreensão da Constituição dos Sentidos. Psicologia Ciência e Profissão, 26 (2), 222-245 - 2006. 
AMORIM, Sérgio Gonçalves de. Contextualização do debate brasileiro acerca das migrações internacionais - Uma análise a partir do caso haitiano. Lindóia/SP - 2012.

BOCK, Ana Mercês Bahia. A Psicologia a caminho do novo século: identidade profissional e compromisso social. Estudos de Psicologia, v. 4, n. 2, p. 315-329, 1999.

BRASIL, MINISTÉRIO DA SAÚDE. Resolução 466/2012 do Conselho Nacional de Saúde/MS Sobre Diretrizes e Normas Regulamentadoras de Pesquisa envolvendo seres humanos. Diário Oficial da União, 12 de dezembro de 2012.

CORREIA, Diego; DE PAULA, Elder Andrade; VALENCIO, Norma. Entre desastres catastróficos e mobilidades controladas: das idas e vindas de camponeses brasileiros à chegada dos imigrantes haitianos no "reino deste mundo amazônico". Revista Semestral do Departamento e do Programa de PósGraduação em Sociologia da UFSCar, v. 3, n. 1, p. 45, 2013.

DANTAS, Sylvia Duarte; UENO, Laura; SUGUIURA, Marcos. Identidade, Migração suas Dimensões Psicossociais. Rev. Inter. Mob. Hum. Brasília, Ano XV1ll, No 34, p. 45 - 60, jan./jun. 2010.

DIAS, Alfrancio Ferreira. A Contribuição dos Estudos Culturais para Compreender o Conceito de Identidade. Anais do V Fórum Identidades e Alteridade Sgepiadde/UFS/Itabaiana - SE, 2011.

DINIZ, Eugenio. O Brasil ea Minustah. Security and Defense Studies Review, v. 5, n. 1, p. 90-108, 2005.

ENUMO, Sônia Regina Fiorim; MOTTA, Alessandra Brunoro. BRINCAR NO HOSPITAL: ESTRATÉGIA DE ENFRENTAMENTO DA HOSPITALIZAÇÃO INFANTIL. Psicologia em Estudo, Maringá, v. 9, n. 1, p. 19-28, 2004.

FIGUEIREDO, Eurídice; NORONHA, Jovita Maria Gerheim. Identidade nacional e identidade cultural. Conceitos de literatura e cultura. Juiz de Fora: UFJF, p. 189-205, 2005.

FERNANDES, Duval e CASTRO, Maria da Consolação Gomes de. A migração haitiana para o Brasil: Resultado da pesquisa no destino. In: ORGANIZACIÓN INTERNACIONAL PARA LAS MIGRACIONES - OIM. Oficina Regional Para América Del Sur. La migración haitiana hacia Brasil: Características, oportunidades y desafíos. Cuadernos Migratorios nº 6, 2014.

FONTANELLA, Bruno Jose Barcellos et al. Amostragem em pesquisas qualitativas: proposta de procedimentos para constatar saturação teórica Sampling in qualitative research: a proposal for procedures to detect theoretical saturation. Cad. Saúde Pública, v. 27, n. 2, p. 389-394, 2011.

FRANKEN, Ieda; COUTINHO, Maria da Penha de Lima; RAMOS, Natália. Migração e qualidade de vida: um estudo psicossocial com brasileiros migrantes. Estudos de Psicologia I Campinas I 26(4) I 419427 I outubro - dezembro 2009.

GUimaro, M. S.; Steinman, M.; Kernkraut, A. M.; SANTOS, O. F. P. dos; LACERdA, S. S. Sofrimento psicológico em sobreviventes do terremoto ocorrido no Haiti em 2010. Trabalho realizado no Hospital Israelita Albert Einstein, São Paulo, SP, Brasil, 2013.

HALL, Stuart. Identidades culturais na pós-modernidade. Rio de Janeiro: DP\&, 1997.

KREUTZ, Lúcio. Identidade Étnica e Processo Escolar. Cadernos de Pesquisa, nº 107, p. 79 - 96, julho/ 1999.

LIMA, Sandra Mara Maciel de; HOPFER, Kátia Regina; SOUZA-LIMA, José Edmilson de. Complementaridade entre racionalidades na construção da identidade profissional. RAE-eletrônica, v. 3, n. 2, p. 1-20, 2004. 
MINAYO, Maria Cecilia de Souza; DESLANDES, Suely Ferreira; NETO CRUZ, Otávio; GOMES, Romeu. Pesquisa Social: Teoria, Método e Criatividade. Petrópolis - RJ - 29 ed. Vozes, 2010.

MORAES, Roque. Análise de conteúdo. Revista Educação, Porto Alegre, v. 22, n. 37, p. 7-32, 1999.

MORAES, Isaias Albertin de; ANDRADE, Carlos Alberto Alencar de; MATTOS, Beatriz Rodrigues Bessa. A IMIGRAÇÃO HAITIANA PARA O BRASIL: CAUSAS E DESAFIOS. Conjuntura Austral, v. 4, n. 20, p. 95-114, 2013.

OLIVEIRA, Roberto Cardoso. Identidade, Etnia e Estrutura Social. Ed. Livraria Pioneira Editora, São Paulo, 1976.

QUIVY, Raymond.; CAMPENHOUDT, L. V. Manuel de recherché en sciences sociales. Tradutores: João Minhoto Marques, Maria Amália Mendes e Maria Carvalho. 4. ed. Paris: Gradiva, 2005.

PACÍFICO, Andrea Pacheco; PINHEIRO, Thaís Kerly Ferreira O status do imigrante haitiano no Brasil após o terremoto de 2010 sob a perspectiva do Pós-Estruturalismo Revista Perspectivas do Desenvolvimento Um enfoque multidimensional, Brasília, 2013.

RODRIGUES, Viviane Mozine. Migrantes Haitianos no Brasil: Mitos e Contradições. 2013.

ROMANELLI, Geraldo. Diálogos sobre prática de pesquisa. Org. Geraldo Romanelli, Zélia M. BiasoliAlves. Ribeirão Preto, Legis Summa, 1998.

SCOLARI, Rosana Mary Delatorre. Ressignificação da identidade através do trabalho e moradia dos catadores de material reciclável da Associação de Recicladores Cidadão Amigos da Natureza do município de Erechim (RS). Dissertação, 2006.

SOARES, Weber. Análise de redes sociais e os fundamentos teóricos da migração internacional. R. Bras. Est. Pop., Campinas, v. 21, n. 1, p. 101-116, jan./jun. 2004.

TAYLOR, Charles. Multiculturalisme. Différence et démocratie. Paris: Flammarion, 1994. THIESSE, Anne-Marie. La création d'identités nationales. Europe XVIII” - XX’ siêcle. Paris: Seuil, 2001.

TARANU, Olga Estudo da Relação entre Resiliência e Espiritualidade numa Amostra Portuguesa, Faculdade de Psicologia e ciência da Educação, Lisboa, 2011.

VERENHITACH, Gabriela; DEITOS, Marc; SEITENFUS, Ricardo. O Brasil ea cooperação triangular sul-sul para o desenvolvimento: o caso do Haiti.Trabalho apresentado no I Simpósio em Relações Internacionais do Programa de Pós-Graduação em Relações Internacionais San Tiago Dantas, p. 12-14, 2007.

WATARAI, Felipe; ROMANELLI, Geraldo. Trabalho e identidade de adolescentes do sexo masculino de camadas populares. Proceedings of the Simpósio Internacional do Adolescente, v. 1, 2005. 